\title{
'Design and Simulation of Engine Operation Temperature Monitor and Control System by Using Internet of Things
}

\author{
Joni D. Sembiring \\ Department of Mechanical Engineering \\ Swiss German University \\ Tangerang 15143, Indonesia \\ Email: jonids@unitedtractors.com
}

\author{
Gembong Baskoro \\ Department of Mechanical Engineering \\ Swiss German University \\ Tangerang 15143, Indonesia
}

\author{
Hanny J. Berchmans \\ Department of Mechanical Engineering \\ Swiss German University \\ Tangerang 15143, Indonesia
}

\begin{abstract}
In this research, it is explained how the development of an online monitoring engine temperature system that is connected with thingspeak. This system was designed and developed to monitor engine temperature. This system is made of several components, namely the Arduino Mega 2560 component which is connected to the LM35 heat sensor, LED, active buzzer, after which the data is stored in the database using the internet network. Data servers things that can be seen using a website besides that data can also be sent to customer users of mobile devices in this case will make the user easier because without opening the website the thingspeak will provide information if something is abnormal or when the temperature exceed standard.
\end{abstract}

Keywords: Thing speak, SMS, engine temperature, arduino mega 2560, SIM900A

\section{INTRODUCTION}

The D375-6R (Fig.1) bulldozer unit is one of Komatsu's superior products and this unit is also a unit with a large population in Indonesia and especially in the mining world. This unit is a chain tractor that is useful for digging, moving, pushing soil or material that can be operated in rocky, hilly and mud soils in various sectors of work such as mining, construction, logging, industrial plantations and plantations

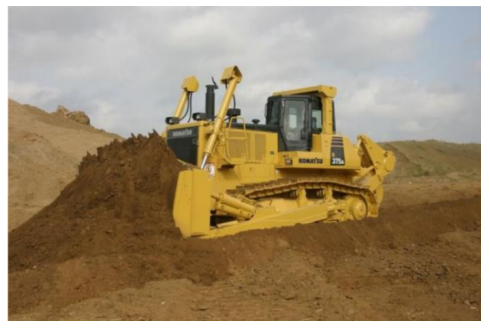

Fig. 1. Unit D375-6R

It is vital that Machine temperature is one of the elements that must be monitored correctly, many cases of engine over- head occur because the lost monitor can still be handled at the beginning. The D375-6R unit for monitoring currently uses 2 systems namely directly from the monitor monitor that can be monitored by the operator currently in operation and also by using KOMTRAC PLUS / VHMS / EQP CARE which can be monitored using the internet or downloaded on direct units.The VHMS (Vehicle Health Monitoring System) is an enhancement from Komatsu that is installed in mining units. VHMS functions to:

1) Detect abnormalities to avoid more severe damage.

2) Extend component life (predicting overhaul time).

3) Detect $\&$ avoid miss operations (overrun, overload etc.).

4) Facilitate analysis of problems that occur (especially in the warranty period)

Data retrieval can be done in 3 ways

1) Manual Download VHMS

Namely: download VHMS data by visiting each machine and using a laptop and download cable to retrieve the VHMS data.

2) Wireless Download VHMS

Namely: downloading VHMS data by utilizing Wifi signals both from the Laptop and from other Wifi devices and downloading is done remotely (no need to go to each Machine). (Fig.2)

3) By monitoring by the Internet by entering the EQP CARE KOMTRAC PLUS / VHMS PLUS web and downloading it from the Web, only for data sent every 00:00 to the cloud that when we retrieve data it is not real time.(Fig.3)

For the VHMS monitor (Fig.2), it only monitors the engine temperature, it can't be real time, so when there is an over head phenomenon and when the operator in the field is insensitive or caring, it will usually be delayed so we need real time so we can know earlier and and can be anticipated so that there is no overhead, this is what prompted me to do this research. In the D375-6R engine uses the SAA6D170E-5 engine where engine coolant uses a coolant in the cooling system and is circulated by a pump then the flow of the coolant will be 


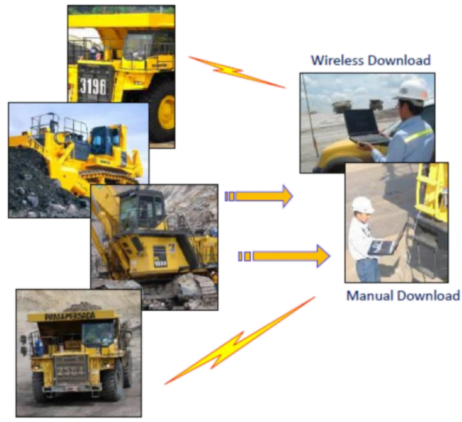

Fig. 2. Take data VHMS

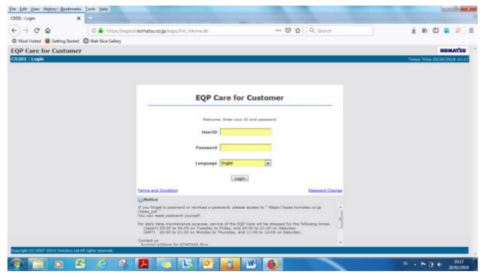

Fig. 3. EQP care web

passed to the thermostat where the thermostat will regulate flow based on temperature if the temperature is above $78^{\circ} \mathrm{C}$ then the thermostat opens radiator to be cooled by a radiator blown by the fan.

\section{RESEARCH PROBlems}

Many events in the field where heavy equipment works and overheating result in high costs due to overhauling, this occurs

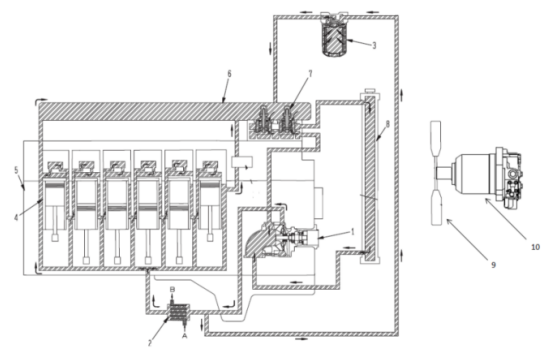

Fig. 4. Cooling system unit D375-6R (1. Water Pump, 2. Oil cooler, 3. Corrosion resistor, 4. Water jacket, 5. Cylinder block, 6. Water manifold, 7. Thermostat, 8. Radiator, 9. Fan, 10. Hydraulic fan motor) because there is no temperature monitoring and no control system

\section{SCOPE}

The problem limits in this study are as follows:

1) prototype design for simulation of temperature control for the engine on the D375-6R

2) Taking test data based on simulations on the prototype made

3) Analysis based on data taken from simulation

4) Methodology

In the design aspect to make a machine temperature monitoring system based on the internet of things (IoT), there are a number of things that need to be done including designing / drawing through pictures and thinking about obstacles that will be faced so that it can facilitate us in completing the tools at the right time.The main material of this tool is the Arduino Mega 2560 microcontroller. Arduino mega 2560 is the main component needed as a data processor and which will regulate the running of the system in the tool. Of course there are additional components so that the system can run properly such as LM 35 temperature sensor, SIM900A Module GSM GPRS SHIELD, Buzzer, Led, AC heater element, Adaptor.

\section{A. Material Use}

1) Temperature sensor LM35

2) Relay

3) Buzzer

4) Led

5) Aluminium plate

6) Heater element AC $220 \mathrm{~V}, 60$ watt

7) Adaptor

8) Arduino mega 2560

9) Module SIM900A GSM GPRS SHIELD

10) Potentiometer

11) Display

\section{B. Electrical Schematic Diagram}

Here is the final design for the system wiring that has been added to the GSM 900A Shield which will connect this system to the internet (Fig.5).

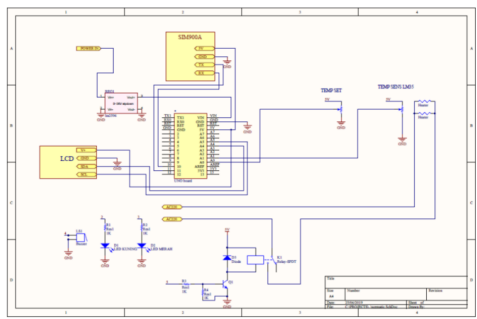

Fig. 5. Electrical schematic diagram 


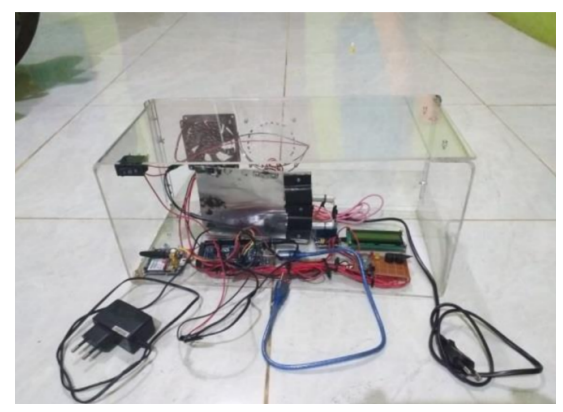

Fig. 6. Final prototype

\section{Final prototype}

After we do the design wiring, it's time to make it happen with a prototype, we connect all the meters starting from the adapter to Arduino 2560, then we connect it to the LED, buzzer and temperature sensor to read the heat, then connect potentio, relay with the heating element type AC $220 \mathrm{~V} 60$ watt as much as 2 and tied on an aluminium plate, then connected to the GSM 900A Shield which will connect the IoT and connect display and also to attract everything to put it in acrylic (Fig.6).

\section{Result \& Discussions}

We can see temperatures above $90^{\circ} \mathrm{C}-115^{\circ} \mathrm{C}$ more sloping than the beginning of $36^{\circ} \mathrm{C}$ until $90^{\circ} \mathrm{C}$, and the temperature is indeed achieved with a duration of 471 seconds. It's just not so stable that the filter is needed to eliminate noise because it will be difficult to read the LCD and it will also be difficult to determine what the actual temperature is, as in the previous theory, using a movable lever filter to stabilise the signal.

$$
y[i]=\frac{1}{M} \sum_{M-1}^{j=0} x[i+j]
$$

From the Figure $7 \& 8$, it looks more stable where the noise is already formed and the temperature of $115^{\circ} \mathrm{C}$ is reached with the same time that is at 470 seconds. Where the measurement is carried out during the day and the temperature starts at $36^{\circ} \mathrm{C}$, and at the beginning between $36^{\circ} \mathrm{C}$ to $90^{\circ} \mathrm{C}$ it takes 170 seconds and from $90^{\circ} \mathrm{C}$ to $115^{\circ} \mathrm{C}$ it takes 300 longer, meaning that the engine will also apply the same where reaching temperatures above $90^{\circ} \mathrm{C}$ will be more difficult if there is up-normal in the system.

This means that with this system we can predict to immediately have an inspection or to predict maintenance. And here is a graph of the comparison between those that have been filtered and those that have not been filtered

In Figure 9, clearly seen that has been filtered (blue) is more stable And it will make it easier for us to read and process data and this shows that our filters work. We can see the red one is less stable where this is caused because the heater used is an

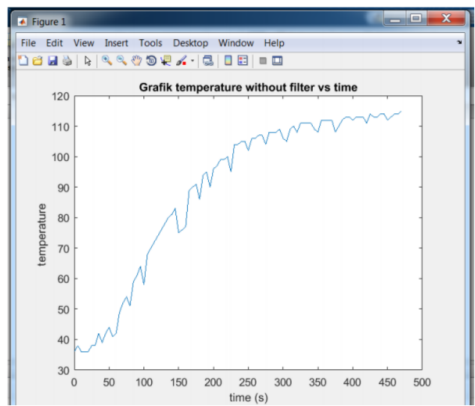

Fig. 7. Result graph temperature without filter

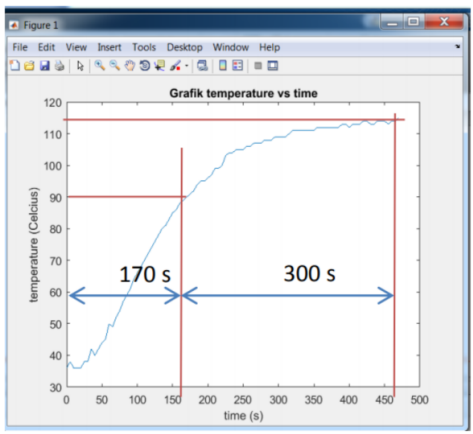

Fig. 8. Result graph temperature with filter

$\mathrm{AC}$ heater where the $\mathrm{AC}$ current has a frequency of $50 \mathrm{~Hz}$ so that the signal that is read by the sensor is less stable. And the following is a table of prototypes that are operated from room temperature until the heater is turned off automatically by the system, this is done to simulate the engine that is operating and recording time from this simulation.

From Figure 10, we can see that the simulation was carried out at a temperature of $36^{\circ} \mathrm{C}$ to reach a temperature of $100^{\circ} \mathrm{C}$ which required 3.37 minutes where at a temperature of $100^{\circ} \mathrm{C}$ the system would send SMS and twitter (Fig.11), and the SMS received at 3.5 minutes, then twitter on Received at 4.3 $\mathrm{m}$, it means faster sending of SMS compared to Twitter, this is caused by Twitter requiring the internet to send messages, while SMS is not, but if the internet signal is better then twitter delivery will be better, this is evident from the writing (33S) where that means sending 33 seconds ago, then to reach a temperature of $105^{\circ} \mathrm{C}$ the light yellow LED lights need 4.16 minutes, to reach a temperature of $110^{\circ} \mathrm{C}$ the red LED lights go on simultaneously the buzzer takes 5.2 minutes, and the heater will be off at 8,03 minutes means the temperature has 


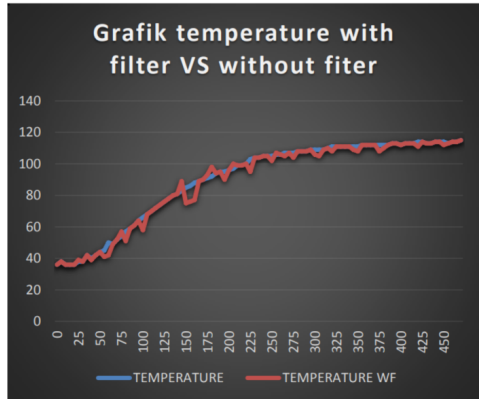

Fig. 9. Graph of the comparison between those that have been filtered and those that have not been filtered

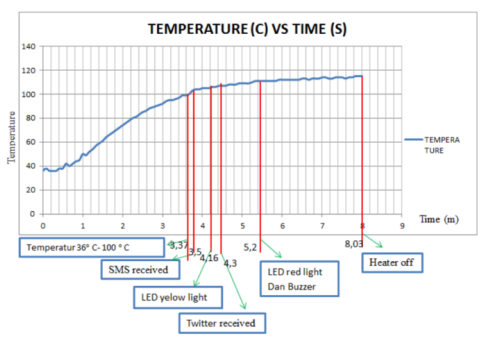

Fig. 10. Graph step operation with time

reached $115^{\circ} \mathrm{C}$ From the graph above where twitter is longer received than SMS this depends on the strength of the internet signal.

\section{CONCLUSIONS AND RECOMMENDATIONS}

We can see temperatures above $90^{\circ} \mathrm{C}-115^{\circ} \mathrm{C}$ more sloping than the beginning of $36^{\circ} \mathrm{C}$ until $90^{\circ} \mathrm{C}$, and the temperature is indeed achieved with a duration of 471 seconds. It's just not so stable that the filter is needed to

\section{A. Conclusions}

The conclusions of this research after the design, simulation and analysis of this system are obtained, which are obtained as follows:

1) From an internet temperature monitoring device compatible with Arduino, the LM 35 sensor works properly

2) The system that is connected to the cloud (thingspeak)

3) Accept cloud as expected questions

4) We can monitor the temperature and control system on the D375-6R engine so that overhaulingcan be anticipated this is good news for customers and my company.

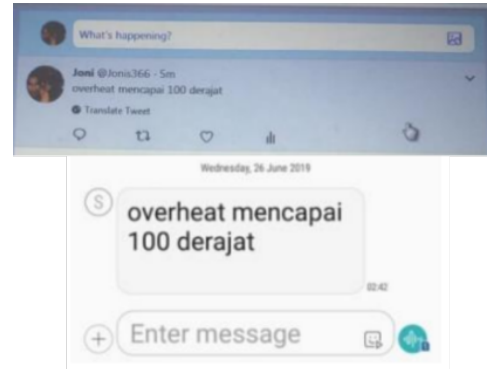

Fig. 11. Graph step operation with time

\section{B. Recommendation}

Some recommendations for this system

1) The author expects this system to be implemented in the D375-6R so that it will increase the selling value of the D375-6R unit, and will also help the customer to monitor the engine temperature control and help extend the life of the D375-6R unit from damage caused by over heat

2) In making this research, the authors expect this to be implemented in the unit because it will greatly help the customer

3) The author expects system developers to be able to add errors from the D375-6R unit that can be added to this system

4) The author hopes that the development of this system can be implemented by other machines.

\section{REFERENCES}

[1] Komatsu, Operation and Maintenance Manual Bulldozer D375-6R

[2] Komatsu, Shop Manual Bulldozer D375A-6R

[3] Indonesia Technology, Pengenalan Tentang Arduino IDE

[4] Mulge, Remote Temperature Monitoring Using Lm35 Sensor And Intimate Android User Via C2dm Service Lm35 1-17,2017

[5] UT School, Diesel engine 1, May 2008

[6] http://www.sinauarduino.com/artikel/esp8266/

[7] https://www.analog.com/media/en/technical-documentation/dsp-book/ dsp_book Ch15.pdf

[8] UT School, Basic Electrical 1, June 2008

[9] Komatsu, Shop Manual Engine SAAD170E-5

[10] Training Center Department, VHMS dan Komtrax, PT United Tractors Tbk

[11] Totok Budioko, System Monitoring Suhu Jarak Jauh Berbasis Internet Of Things Seminar Riset Teknologi Informasi (SRITI), 2016 